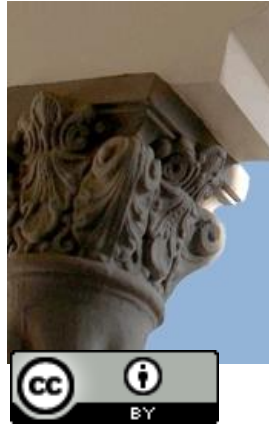

\title{
Fundamentalismos ortodoxos e democracia liberal: o bem comum na teologia de Aristotle Papanikolaou
}

\author{
Orthodox Fundamentalisms and Liberal Democracy: the common \\ good in Aristotle Papanikolaou's theology
}

Graham McGeoch*

\begin{abstract}
Resumo
Notando que originalmente fundamentalismo é um termo técnico para descrever um certo tipo de protestantismo norte-americano, este artigo reconhece que fundamentalismo se aplica a grupos mais amplos (ainda que de forma técnica) para descrever vários grupos religiosos, e até sistemas econômicos e políticos. Este artigo propõe discutir a teologia política de Aristotle Papanikolaou, teólogo ortodoxo, no contexto da democracia liberal. Especificamente, o artigo foca na discussão do bem comum que Papanikolaou apresenta fundamentada no conceito de comunhão divina-humana. A teologia política de Aristotle Papanikolaou engaja com influentes teólogos da tradição ortodoxa tais como Máximos, o Confessor, e John Zizioulas. Deste modo, sua discussão do bem comum fundamenta-se numa tradição teológica que investiga os conceitos cristãos de amor e pessoa [personhood].
\end{abstract}

Palavras-chave: Teologia ortodoxa. Teologia política. Democracia liberal. Bem comum.

\begin{abstract}
Noting that originally fundamentalism is a technical term to describe a certain kind of north American Protestantism, this article recognizes that fundamentalism is applied to wider groups (still in a technical form) to describe various religious groups, and even economic and political systems. This article proposes to discuss the political theology of Aristotle Papanikolaou, an Orthodox theologian, in the context of liberal democracy. The article specifically focuses on his discussion of the common good, which Papanikolaou presents based on the concept of divinehuman communion. The political theology of Aristotle Papanikolaou engages with influential theologians from the Orthodox tradition, including Maximus, the Confessor and John Zizioulas. As such, his discussion of the common good is grounded in a theological tradition which investigates the Christian concepts of love and personhood.
\end{abstract}

Keywords: Orthodox theology. Political theology. Liberal democracy. Common good.

Artigo submetido em 27 de julho de 2020 e aprovado em 8 de maio de 2021.

Doutor em Teologia pela University of Glasgow. Professor da FUV. País de origem: Escócia. E-mail: graham@fuv.edu.br 


\section{Introdução}

Histórica e teologicamente, fundamentalismo é um termo técnico para descrever um certo tipo de protestantismo norte-americano. George Marsden (1980) descreveu fundamentalismo em relação a várias correntes e movimentos protestantes norte-americanos (MARSDEN, 1980). Apesar desta restrição técnica, o termo fundamentalismo tem sido aplicado a outros grupos cristãos, notavelmente os ortodoxos ${ }^{1}$. Também, é amplamente usado para descrever tipos de posturas religiosas de variadas religiões entre quais destacamos islam, judaísmo, hinduísmo e budismo.

Em tempos mais recentes, o interesse no termo fundamentalismo foi despertado pela Revolução Iraniana (1978-79). The Fundamentalism Project liderado por Martin E. Marty e R. Scott Appleby produziu 5 volumes de reflexões sobre fundamentalismo e suas expressões. Na literatura, há um certo consenso que fundamentalismo é um produto da modernidade (APPBLEBY, 2020). Appleby, e outros, particularmente Vasilios N. Makrides, questionam a aplicabilidade do termo fundamentalista aos ortodoxos. Makrides (2016) prefere o termo rigorist porque a Ortodoxia não compreende a si mesma como fruto da modernidade, mas contesta a própria modernidade (MAKRIDES, 2016). Por sua vez, Appleby (2020) nota que as categorias usadas por Makrides para delimitar rigorismo poderiam ser citações diretas da lógica ideológica e social do fundamentalismo (APPLEBY, 2020).

O termo fundamentalista também se aplica a sistemas econômicos (o fundamentalismo do mercado neoliberal) e sistemas políticos (o fundamentalismo da democracia liberal). Sendo assim, "fundamentalismo" não se restringe mais somente à esfera religiosa. Fundamentalismo, é um termo (ainda que técnico) usado para expressar "hegemonias”, "intolerâncias” e certas “cegueiras" de sistemas religiosos, econômicos e políticos.

Konstantinos Delikostantis (2017) situa este fenômeno no fato que igrejas ortodoxas interagem com um mundo influenciado pela modernidade (interpretado como iluminismo ocidental), e ao mesmo tempo se posicionam contra alguns fundamentos deste mundo tais como liberalismo, direitos humanos, secularismo e pluralismo (DELIKOSTANTIS, 2017). 
Geralmente, o termo fundamentalismo não é usado pelos próprios fundamentalistas ${ }^{2}$. É um termo usado amplamente pela academia para descrever grupos "oposicionistas", religiosidades que rejeitam a virada hermenêutica da religião e que contestam a base plural da democracia liberal (MARTY, 1992). Apesar dos ataques populares ao fundamentalismo da democracia liberal, por Tariq Ali (2002) por exemplo, geralmente o termo fundamentalismo é usado pelo discurso da democracia liberal para descrever religiosidades que contestam, rejeitam ou desviam do pensamento (e teologia) ocidental que fundamenta a democracia liberal.

Para estender essa lógica mais a fundo, fundamentalismo poderia aparecer na literatura como uma forma de mostrar a incompatibilidade de certos tipos de religiosidades com a democracia liberal. Por exemplo, o desejo dos islamistas (frequentemente apresentados como fundamentalistas islâmicos apesar da grande maioria dos muçulmanos rejeitarem associações entre islamismo e islam) de criar um califado é interpretado pela democracia liberal como um projeto teocrático que necessariamente ameaça as bases plurais de sociedades. Outro exemplo é a teologia política da teologia ortodoxa. A "sinfonia” apresenta um modelo teológico preferencial para organizar a política, especialmente em “países ortodoxos”. Nikolas K Gvosdev (2000) demonstra que esta preferência teológica não se manifesta na prática. Ele indica que quando “países ortodoxos” tiveram opção de escolha de sistema político no século XX Etiópia, Grécia, etc. - as populações sempre votaram para democracia liberal e rejeitaram a "sinfonia" (GVOSDEV, 2000). Novamente, a democracia liberal interpreta tal formulação como incompatível com o exercício de princípios democráticos.

Edward Said (2003) oferece uma crítica mais incisa sobre esses olhares da democracia liberal aos outros (islam e cristianismo ortodoxo nos casos acima citados), e da conclusão da democracia liberal sobre a incompatibilidade de outras propostas teológicas e filosóficas (SAID, 2003). “Orientalismo” é uma atitude ocidental para com o oriente. Assim, o oriente é uma invenção do próprio ocidente, onde o outro, o exótico e a barbárie são projetados. Nesta

\footnotetext{
${ }^{2}$ A exceção é The Fundamentals: A Testimony to the Truth (1910-15), que é uma série de panfletos escritos por lideranças conservadoras no século XX nos Estado Unidos.
} 
visão, o oriente é fundamentalmente diferente (incompatível e inferior) ao ocidente. Portanto, a lógica é que religiões orientais, tais como islam e cristianismo ortodoxo, sejam incompatíveis com a democracia liberal ocidental. São fundamentalismos no sentido "oposicionista", que contesta, rejeita ou até mesmo desvia do pensamento e teologia ocidentais.

Teologicamente, “orientalismo” exerce muita influência no ocidente. Tradicionalmente, a teologia trabalha com cristianismos ocidentais e orientais. Anna Marie Aagaard e Peter Bouteneff (2001) notaram que há uma grande divisão entre o cristianismo oriental e ocidental, e, ao mesmo tempo que estas são categorias errôneas para entender a divisão (AAGAARD; BOUTANEFF, 2001). Em manuais de teologia, traça-se uma divisão no ano simbólico de 1054. Outros traçam a linha divisória à era patrística entre a igreja latina e a igreja grega. Mais recentemente, teólogas como Sarah Coakley (2013) tem problematizado e questionado essa divisão teológica e o "orientalismo" eclesial que a acompanha, notando que teologias da igreja primitiva não seguem esta divisão teológica e não são usadas desta forma orientalista também (seja na teologia ocidental ou na oriental) (COAKLEY, 2013).

"Orientalismo" como paradigma interpretativo do outro religioso, seja islam ou cristianismo ortodoxo, coloca esse outro religioso numa posição inferior e, frequentemente, incompatível com valores ou tradições da democracia liberal. Assim, nasce a confusão na interpretação do outro enquanto expressão de "fundamentalismo" em termos de contestação, rejeição ou desvio do pensamento (e de algumas teologias) ocidental que fundamentam a democracia liberal. Ou seja, "orientalismo" cria seus "fundamentalismos", seus grupos "oposicionistas”, religiosidades que rejeitam a virada hermenêutica da religião e que contestam a base plural da democracia liberal.

\section{Teologia política ortodoxa}

No seu livro, The Mystical as Political (A Mística como Política), o teólogo ortodoxo Aristotle Papanikolaou (2014) tem refletido sobre a relação entre teologia e política (democracia liberal) (PAPANIKOLAOU, 2014). Deve-se afirmar desde já que Papanikolaou é a favor da democracia liberal. Porém, ele é 
a favor da democracia liberal por razões teológicas internas à teologia ortodoxa. Ou seja, a opinião favorável de Papanikolaou é informada por um contexto supostamente contrário (e às vezes contra) à democracia liberal ocidental. Ciente disso, Papanikolaou identificou três grandes áreas de debate (ou fricção) entre teologia ortodoxa e propostas da democracia liberal. Em primeira instância, estão as noções básicas que fundamentam a democracia liberal. Em segunda, está o discurso da democracia liberal sobre direitos humanos. Em terceira, está o conceito de bem comum em discursos filosóficos e teológicos ocidentais.

Aristotle Papanikolaou e seu colega George Demacopoulos (2017) afirmam que não há igreja ortodoxa no mundo de hoje que repudia a democracia (DEMACOPOULOS; PAPNIKOLAOU, 2017). Onde existe debate e fricção, esses estão relacionados ao tipo de democracia vivida, e, especificamente, a relação entre Igreja-Estado. Em termos teológicos a fricção ortodoxa em relação às noções básicas que fundamentam a democracia liberal remete à relação entre teologia ortodoxa e modernidade ocidental. Resumidamente, a rejeição da modernidade ocidental, e, particularmente, sua entrada na teologia, é articulada mais claramente na teologia de Georges Florovsky e a assim chamada síntese neo-patrística. Florovsky relega qualquer teologia influenciada por filosofias e conceitos modernos ocidentais à categoria de filosofia religiosa (GAVRILYUK, 2015,). Deste modo, Sergius Bulgakov, entre os mais importantes teólogos políticos da tradição ortodoxa, é frequentemente ainda rotulado e interpretado como filósofo religioso em vez de teólogo.

A fricção da teologia ortodoxa diante das noções básicas da democracia liberal frequentemente se expressa nos debates sobre os discursos de direitos humanos. O posicionamento da Igreja Ortodoxa Russa articulado no documento The Russian Orthodox Church's Basic Teaching on Human Dignity, Freedom and Rights [O Ensino Básico da Igreja Ortodoxa Russa sobre Dignidade, Liberdade e Direitos Humanos] talvez seja o caso mais emblemático nos debates atuais. $\mathrm{O}$ documento afirma que:

No mundo de hoje há uma convicção amplamente compartilhada que a instituição de direitos humanos em si poderia promover da melhor maneira o desenvolvimento da personalidade humana e organização 
social. Ao mesmo tempo, as vezes a defesa de direitos humanos é usada como argumento para realizar ideias que na sua essência radicalmente discordam com ensino cristão. Deste modo, cristãos têm sido colocados em situações onde estruturas públicas e sociais os obrigam a pensar e agir contra os mandamentos de Deus, portanto, impedindo seu caminho em direção ao mais importante objeto da vida humana, que é a libertação do pecado e a descoberta da salvação. Nesta situação, a Igreja, com base nas Escrituras e Tradição Sagrada, tem que lembrar as afirmações básicas do ensino cristão sobre o ser humano e avaliar a teoria de direitos humanos e seu uso. (THE RUSSIAN ORTODOX CHURCH'S BASIC TEACHING ON HUMAN DIGNITY, FREEDOM AND RIGHTS, 2008, p. 1, tradução nossa).3

A preferência da Igreja Ortodoxa Russa é falar em "dignidade humana" em vez de "direitos humanos". Aristotle Papanikolaou (2014) localiza essa "desconfiança” do discurso de direitos humanos em teologias ortodoxas em três princípios (PAPANIKOLAOU, 2014). Primeiro, as afinidades filosóficas entre humanismo ateu e direitos humanos. No caso da Igreja Ortodoxa Russa (e outras igrejas ortodoxas do leste europeu) essa leitura é influenciada pelas experiências negativas - até catastróficas - das igrejas sob regimes comunistas (e comunismo é interpretado como um dos humanismos ateus). Segundo, a lógica da razão pública que busca excluir religião da vida pública. Novamente, a vivência sob regimes que já tentaram eliminar a religião dos povos da União Soviética e do Leste Europeu e as perseguições das igrejas influencia o combate pela teologia ortodoxa do paradigma de religião privada versus vida pública articulada pela razão pública. Terceiro, o fato que a linguagem de direitos humanos se baseia numa antropologia individualista alheio à antropologia teológica cristã.

Há várias reflexões disponíveis de teólogos e teólogas ortodoxos(as) sobre questões das noções básicas que fundamentam a democracia liberal e o discurso de direitos humanos (YANNARAS, 2004). A contribuição de Aristotle Papanikolaou é uma das tentativas de responder à realidade concreta de igrejas ortodoxas despreparadas para política pós-comunista, e, ao mesmo tempo, de articular uma crítica à teologias ocidentais que tentam emprestar a noção de

\footnotetext{
${ }^{3}$ In the world today there is a widespread conviction that the human rights institution in itself can promote in the best possible way the development of human personality and social organization. At the same time, human rights protection is often used as a plea to realize ideas which in essence radically disagree with Christian teaching. Christians have found themselves in a situation where public and social structures can force and often have already forced them to think and act contrary to God's commandments, thus obstructing their way towards the most important goal in human life, which is deliverance from sin and finding salvation. In this situation the Church, on the basis of Holy Scriptures and the Holy Tradition, has to recall the basic affirmations of Christian teaching on the human person and to assess the theory of human rights and its use.
} 
"deificação" da teologia ortodoxa para criticar a democracia liberal. "Deificação" é um termo central para a teologia ortodoxa. É atribuído aos trabalhos teológicos de Gregório de Palamas e Vladimir Lossky. Ela é “uma transfiguração do [ser humano] por meio da comunhão com Deus [...] (theosis) [...] era o centro da vida espiritual do Oriente cristão.” (ALFEYEV, 2018, p. 279).

Ele não é o único teólogo ortodoxo atualmente pensando sobre teologia política. Pantelis Kalaitzidis (2012) também se preocupa com a mesma questão desta forma: por que a ortodoxia não tem desenvolvido uma teologia política (ou teologia de libertação) (KALAITZIDIS, 2012)? Kalaitzidis localiza o problema na "teologia-étnica" da ortodoxia (uma espécie de teologia contextual, de acordo com Kalaitzidis). A teologia-étnica expõe a primazia do étnico/nacional acima do teológico/eclesial. Assim, frequentemente a teologia (política) ortodoxa se expressa em termos "neo-nacionalistas", "neoconservadores”, “anti-ocidentais", “anti-modernos” e “anti-pluralistas” (KALIATZIDIS, 2012, p. 81).

\section{Aristotle Papnaikolaou e o "bem comum"}

Aristotle Papanikolaou também está ciente deste perigo contextual ortodoxo apontado pelo Kalaitzidis. Ele procura no conceito de "bem comum" uma maneira de superar as dificuldades étnicas/nacionais que as vezes permeiam teologias ortodoxas. Também, diferentemente de teólogos ocidentais, Papanikolaou situa a discussão sobre o "bem comum" firmemente no campo da teologia e não da filosofia.

Na tradição ocidental da democracia liberal o "bem comum" é associado ao pensamento de Jean Jacques Rousseau, entre outros (ROUSSEAU, 2010). Frequentemente, teólogos ocidentais, principalmente da assim chamada "teologia pública", trabalham em prol da democracia liberal oferecendo verificações teológicas para fundamentos já estabelecidos pela filosofia ocidental em relação às noções básicas da democracia liberal, do discurso da democracia liberal sobre direitos humanos e do conceito de bem comum. Um exemplo disso é o trabalho de Miroslav Volf (2011). No Brasil, o trabalho do Rudolf von Sinner (2012) é pioneiro nesta área. 
Uma das dificuldades apresentadas por essas abordagens ocidentais (representadas por Volf e von Sinner) é que elas pressupõem pelo menos uma certa afinidade (ou caminhada comum) entre teologia e filosofia ocidental. As vezes o desconforto expresso por certas vertentes do cristianismo brasileiro diante da democracia liberal é precisamente por causa desta afinidade oculta na teologia ocidental. Frequentemente isso é articulado com maior veemência na rejeição do discurso de direitos humanos, do questionamento do bem comum e de ataques à noção geral de democracia liberal. Tal postura se baseia num grito de oposição sobre a entrada da filosofia - interpretada como ateia - na teologia interpretada como revelação divina. Nisto, as oposições brasileiras (fundamentalismos nos termos esboçados acima) não são tão diferentes de algumas oposições ortodoxas.

As oposições fundamentalistas apontam para uma ausência epistêmica. Neste caso, é apontada a percebida ausência teológica nos fundamentos da democracia liberal, no discurso de direitos humanos e do bem comum. Fundamentalismos brasileiros evangélicos compartilham esta postura com fundamentalismos ortodoxos4. Aqui não discutimos se tal leitura é verificada pela literatura. Porém, essa percebida ausência teológica nos fundamentos da democracia liberal também tem sido apontada por teólogos e teólogas ocidentais (não fundamentalistas); talvez de forma mais clara e radical no "movimento" de ortodoxia radical e os escritos de John Milbank (2006). Por isso, a decisão de Papanikolaou de abordar o "bem comum" teologicamente é inovadora e oportuna.

\section{A teologia do "bem comum"}

Papanikolaou está ciente do paradigma atual em muitos debates sobre teologia política. Por um lado, há a força da "razão pública" que procura controlar (o que pode ser envolver ou excluir) a religião, mas é uma religião esvaziada do seu compromisso teológico. Nestes termos, a proposta pública convida a religião a ocupar a consciência moral da sociedade, mas a proposta pública está desconfortável com a religião como articuladora do "bem comum"

\footnotetext{
4 Deve-se notar que um dos textos fundadores desta tradição ocidental da democracia liberal é na verdade um tratado teológico de John Locke. Não pretendemos discutir isso aqui. Apenas notamos que leituras fundamentalistas ou desconhecem Locke ou o leem como filósofo ateu.
} 
teologicamente, interpretando tais visões teológicas como automaticamente teocráticas.

A crítica da razão pública tem certo fundamento já que muitas teologias políticas estão seduzidas pelo caminho teocrático. Por exemplo, "Brasil acima de tudo; Deus acima de todos" 5 combina elementos (combustíveis) da primazia do étnico/nacional e de teocracia. Na compreensão de Papanikolaou, impulsos teocráticos e teologia étnico/nacional frequentemente desvelam que cristãos, supostamente motivados pelo amor, e especificamente o amor ao próximo, na verdade agem (ou reagem) ao contexto político motivados pelo medo, raiva e ódio. Ele aponta que teologias políticas geralmente dependem da pressuposição que cristãos agirão como cristãos no contexto político, isso é, motivados pelo amor, caridade e solidariedade com o outro. Papanikolaou salienta que isso é uma projeção idealizada. Na prática, muitas vezes cristãos não agem como cristãos deveriam agir e estão motivados, ao contrário, pelo medo, raiva e ódio do outro. A maioria das teologias políticas não partem desta realidade política contrária ao "mandamento do amor", preferindo as teorias teológicas idealizadas do amor à realidade do ódio dos cristãos.

Por outro lado, Papanikolaou nota que as ontologias cristãs, principalmente católico-romanas (da teologia natural) e protestantes (de certa rejeição ou diálogo crítico da filosofia iluminista), afirmam que a ontologia cristã e ontologia política são fundamentalmente diferentes e irreconciliáveis. (É uma espécie de inversão teológica da rejeição feita pela razão pública da teologia). Nesta perspectiva, o esforço cristão é trazer uma visão “particular” e "particularmente" cristã ao debate e, ao mesmo tempo, rejeitar qualquer acomodação com visões políticas interpretadas como não cristãs (e ateias). Nesta linha, as contribuições teológicas à política geralmente se reduzem à tentativas de esclarecer como fundamentar argumentos para a rejeição (ou aceitação) do secular ou da política. A rejeição teológica total é uma posição do fundamentalismo teológico. Uma rejeição parcial (embora que articulada em termos de aceitação tácita) tais como 'o que falta à democracia liberal sem uma base teológica é....' ainda seja um argumento contra o secular ou a política já que sublinha as limitações da democracia liberal.

5 Este foi o lema de um dos candidatos à Presidência da República nas eleições de 2018 no Brasil. 
Papaninkolaou reconhece as grandes contribuições de John Rawls, Charles Taylor, Richard Rorty, entre outros (da razão pública) e dos teólogos Stanley Hauerwas, John Milbank, Graham Ward, Charles Matthewes ao debate sobre "bem comum". No seu capítulo sobre o "bem comum" ele cita todos; e discorda de todos, sinalizando as limitações de cada tentativa. Ele prefere propostas da teologia ortodoxa para construir o "bem comum", principalmente a ideia de amor em Máximos, o Confessor (PALMER; SHERRARD; WARE, 1984), a ideia de pessoa [personhood] de John Zizioulas ${ }^{6}$, e a ideia de política de Sergius Bulgakov (2008).

\section{0 "bem comum": amor, pessoa e política}

\subsection{Amor}

Máximos, o Confessor (580-662) é um teólogo de muita influência na teologia ortodoxa. Ele ocupa um lugar de destaque no Filocalia, uma coleção de escritos espirituais ou teológicos entre o século IV e XV (PALMER; SHERRARD; WARE, 1984). Ele é o teólogo do amor, escrevendo Os Quatrocentos Capítulos sobre Amor no Filocalia (PALMER; SHERRARD; WARE, 1984). Máximos, o Confessor, é interpretado por Papanikolaou em termos de teologia política. O conceito de amor que Máximos, o Confessor, desenvolve tem muita relevância teológica para a política.

No primeiro capítulo dos Quatrocentos Capítulos sobre Amor, Máximos, o Confessor, escreve que a pessoa que ama Deus, necessariamente, ama todos os outros seres humanos como a si mesmo (PALMER; SHERRARD; WARE, 1984). E se alguém possui ódio no coração contra outros seres humanos (independentemente da falha cometida ou sentida), ele é separado de Deus porque amar a Deus impede odiar outro ser humano (PALMER; SHERRARD; WARE, 1984). Obviamente, conceitos teológicos tais como "unidade" e “comunhão" estão fundamentados pelo conceito de amor em Máximos. Deus é uno e triuno, e o ser humano comunga com a "unidade” de Deus numa relação

\footnotetext{
${ }^{6}$ O trabalho de Zizioulas (1985) nunca foi publicado em português. Em espanhol, o conceito teológico central de Zizioulas, "personhood", é traduzido como "persona". Aqui traduzimos "personhood" como "pessoa", cientes das limitações dessa tradução.
} 
de divina-humana comunhão, às vezes chamada "deificação" na teologia ortodoxa.

Inspirado pelas Escrituras, Máximos, o Confessor lembra o mandamento de amor no Evangelho de João, amem uns aos outros (Jo 15,12). Ele conclui que aquele que não guarda o mandamento de amar seu próximo não pode amar Deus (PALMER; SHERRARD; WARE, 1984). Do mesmo modo, como Deus ama todos os seres humanos como sua criação de forma igual, todos os seres humanos que amam Deus também amam igualmente seu próximo (PALMER; SHERRARD; WARE, 1984). Aqui, Máximos, o Confessor aponta para a indivisibilidade (unidade) do amor de Deus. De acordo com Máximos, o Confessor, os seres humanos reconhecem o amor em atos de caridade (especificamente, dando dinheiro aos pobres), em conselhos espirituais e cuidados de pessoas com necessidades físicas especiais (PALMER; SHERRARD; WARE, 1984).

Esta parte do texto é a parte política na leitura do Papanikolaou. Amor é prático e amor pode ser medido e percebido nos atos dos cristãos com e diante de outros seres humanos. De acordo com Papanikolaou, os dois lugares clássicos da manifestação deste amor são na igreja (ecclesia) e na política (polis). Em tratar da teologia política de Sergius Bulgakvo (abaixo), entraremos mais nesta questão. Aqui, em relação ao Máximos, o Confessor, é preciso apenas notar que a presença de amor manifestada na igreja e na política é basicamente a mesma coisa de dizer que Deus está presente na igreja e na política. É uma base teológica, sem necessariamente ser teocrática (SCHMEMANN, 1963), para a vida eclesial e política. A questão dessa diferença é tratada por, entre outros, Alexander Schmemann, quando ele escreve que igreja não pode criar uma teocracia porque uma teocracia transforma a igreja de uma comunidade de crentes para uma comunidade obrigada a crer. De acordo com Schmemann, uma pessoa obrigada a crer implica uma 'força' ou 'violência' que é necessariamente contrário ao amor.

Daí a importância da observação do Máximos, o Confessor, em relação ao amor. Quem ama Deus e incansavelmente procura Deus em todas as coisas não tem como odiar ou pensar mal de alguém. O ódio e o mal (pelo menos para 
Máximos, o Confessor) é contrário ao amor e sinaliza uma ausência de Deus (PALMER; SHERRARD; WARE, 1984). Assim, uma expressão de irritação, um insulto, ou até humilhação do outro separa os seres humanos do amor e, mais ainda, coloca o ser humano no reino [realm] do ódio (PALMER; SHERRARD; WARE, 1984). Do Máximos, o Confessor, Papanikolaou tira a percepção de que a política (como a igreja) precisa ser construída e vivida a partir do reino de amor e não do reino do ódio, pelo menos se quer ser reconhecida como uma teologia política cristã.

\subsection{Pessoa (Personhood)}

O conceito de amor desenvolvido por Máximos, o Confessor, claramente depende de uma conceituação teológica da pessoa (personhood). Papanikolaou trata desta questão de forma mais compreensiva no capítulo 3 do seu livro. (Neste artigo estamos focando mais no capítulo 4 e a discussão do "bem comum”). Porém, o argumento de capítulo 3 informa a discussão no capítulo 4, inclusive o uso de “pessoa” na discussão do "bem comum”.

Como quase toda teologia ortodoxa contemporânea, o conceito de pessoa deve muito ao teólogo John Zizioulas e seu livro Being as Communion (1985) Papanikolaou (2014) afirma que é apenas no século XX que a teologia cristã, de forma explícita, manifesta apreço para o fato de que Deus é um ser de (três) pessoas em comunhão, e, portanto, qualquer compreensão teológica do ser humano precisa seguir o modelo trinitário em afirmar a reciprocidade relacional e comunhão do ser humano (PAPANIKOLAOU, 2014). Em termos de teologia ortodoxa, Papanikolaou identifica a teologia Vladimir Soloviev, Sergius Bulgakov, Vladimir Lossky, Christos Yannaras e John Zizioulas como importantes contribuições ao debate. (No mundo ocidental, as teologias de Jurgen Moltmann (2013), Leonardo Boff (1986) e Miroslav Volf (1997), as assim chamadas teologias trinitárias sociais, seguem um caminho parecido, porém, distinto, do caminho esboçado por Papanikolaou.

Nas teologias ortodoxas o conceito de pessoa está intimamente ligado a duas doutrinas: a trindade e antropologia. Ou seja, a doutrina da trindade

\footnotetext{
7 Como citado acima, o livro não existe em português. Em Espanhol, foi traduzido como Comunión e Alteridade: persona e iglesia e a introdução à versão espanhola enfatiza a questão da pessoa como 'um ser eclesial'.
} 
necessariamente contempla a pessoa, da mesma forma que a antropologia contempla Deus. Para Zizioulas (1985), esta realidade se expressa na eucaristia (a experiência relacional entre a pessoa e Deus e entre as pessoas de Deus).

Isto quer dizer que tentativas humanas de "constituir juntos", "abertura ao outro", etc não constituem a catolicidade da Igreja, mas que nenhum plano progressivo para um movimento em direção a catolicidade é alcançável puramente no nível histórico e sociológico. A comunidade eucarística constitui um sinal do fato que o eschaton poderia apenas irromper a história, mas nunca seja identificado com ela. (ZIZIOULAS, 1985, p. 161).

É um momento eclesial (PAPANIKOLAOU, 2014). Também, para Zizioulas, a noção de pessoa aponta para uma compreensão do transcendente. De acordo com Zizioulas, todo ser humano anseia para o transcendente. Isto é, na leitura de Papanikolaou (2014), toda pessoa tem saudade de afirmar sua unicidade e autonomia de forma realizada (PAPANIKOLAOU, 2014). A saudade realizada do transcendente é o momento político.

Dessa base da teologia do Zizioulas, Papanikolaou nota que para Zizioulas há uma diferença entre "pessoa" e "indivíduo". O conceito de "indivíduo" sugere uma certa instrumentalização do ser humano, onde é possível se tornar "indivíduo" através de força própria. Assim, o "indivíduo" é marcado pela violência (força) de "controlar" ou "dominar" a realidade em volta. Lembrando o argumento de Máximos, o Confessor, um ato violento não pode ser baseado no amor porque este tipo de autonomia do indivíduo nega a unidade. Neste caso, o indivíduo se definiria “contra” e não “com” o outro.

Para Papanikolaou e Zizioulas, "pessoa” imbui a criação com unicidade e reciprocidade relacional. O conceito de "pessoa" torna cada ser humano presente diante de Deus, de si mesmo e do outro. Esta reciprocidade relacional fundamenta o conceito de "pessoa" de Zizioulas. Papanikolaou utiliza o conceito conforme elaborado por Zizioulas para a teologia política. O "bem comum" de Papanikolaou reconhece "pessoa" e não "indivíduo" como a base da política. Nesta perspectiva a política tem um elemento escatológico, o "bem comum" ajuda a pessoa ansiar para o transcendente porque é apenas na afirmação da unicidade e reciprocidade relacional de cada pessoa que a saudade é realizada. 


\subsection{Política}

Papanikolaou não tem o propósito de oferecer uma perspectiva ortodoxa sobre a teologia política. Ele busca superar as incoerências internas das propostas da "razão pública" e das teologias políticas que dialogam com esta "razão pública" e as vezes até repudiam ontologicamente a política da "razão pública" na sua expressão de democracia liberal, o discurso de direitos humanos e o "bem comum”. Já notamos que vários teólogos ortodoxos insistem que a teologia ortodoxa tem uma relação diferente (até distinta) com a modernidade europeia do que com a teologia ocidental. A teologia ortodoxa é influenciada pela modernidade europeia, principalmente no pensamento de Vladimir Soloviev e Sergius Bulgakov que por sua vez exercem uma grande influência em teologias políticas ortodoxas.

Vladimir Soloviev (2015) advogava uma comunhão divina-humana baseada no princípio de uma "livre teocracia". Nisto ele defendia (na Rússia no século XIX) a separação de Igreja-Estado, o discurso de direitos humanos e pluralismo religioso (SOLOVIEV, 2015). Papanikolaou (2014) observa que para Soloviev, "a realização do divino na realidade criada depende do livre, esforço ascético da pessoa" (PAPANIKOLAOU, 2014, p. 34). Comunhão divina-humana curiosamente depende de liberdade para Soloviev (2015), por isso ele propõe a "livre teocracia". Deus está presente e ausente ao mesmo tempo da vivência desta comunhão divina-humana para Soloviev. Deus está presente no conceito de teocracia (aqui ele usa a palavra de forma diferenciada (benigna) da razão secular para argumentar para a necessidade de fundamentar a política no amor). Mas Deus está ausente pela possibilidade de uma decisão livre (amorosa) de uma pessoa de rejeitar Deus.

Sergius Bulgakov (grande discípulo de Soloviev) escreveu com mais urgência. Ele viveu no período da Revolução Russa e enxergava a falha do sistema político na opressão dos pobres. Ao mesmo tempo, ele se revoltava com a falha da igreja institucional em libertar o povo russo. Desse período tumultuoso, Bulgakov escreveu sua teologia política no livro The Lamb of God [O Cordeiro de Deus] (2008). Ele logo faz uma distinção entre o eclesial e o político que Papanikolaou também vai usar. A verdadeira igreja não pode ser 
identificada apenas com a igreja institucional da Rússia. O eclesial é uma comunhão de liberdade e dignidade. Não pode ser obrigatório, forçado ou despótico (PAPANIKOLAOU, 2014). A política, que para o cristão é um reflexo do eclesial, tem que demonstrar as mesmas características. Porém, enquanto ela é reflexo do eclesial ela necessariamente não é o eclesial. Ou seja, nas palavras de Papanikolaou:

[...] o cristão tem que aceitar certas restrições na esfera pública que não são operativas numa dada comunidade cristã, e tais restrições não são impostas do exterior, mas são consequências lógicas do princípio da comunhão divina-humana. (PAPANIKOLAOU, 2014, p. 159, tradução nossa). ${ }^{8}$

A contribuição do Bulgakov demonstra que o político e o eclesial são distintos. Porém, não são distintos por consequência de construções com bases legais (razão pública) ou pressupostos filosóficos (a grande maioria das teologias políticas contemporâneas). Para Papanikolaou (entre outros teólogo ortodoxos, inclusive Bulgakov) o político tem um conteúdo eclesial mas não se restringe ao eclesial. Se for assim, o político seria simplesmente o eclesial e Papanikolaou e Bulgakov rejeitam essa possibilidade. Além, de ser interpretado como um lugar realizável de "pessoa", o político é o lugar do exercício da transcendência e da liberdade (a possibilidade de rejeitar Deus).

Como observa Papanikolaou surge um paradoxo aqui. "O esforço cristão à comunhão com Deus [...] curiosamente precisa se esforçar para maximizar as condições para a possibilidade de rejeitar Deus” (PAPANIKOLAOU, 2014, p. 142). É nesta diferença (e paradoxo) que Papanikolaou identifica o papel do "bem comum” na teologia política. Por um lado, a política precisa oferecer (para o cristão) a convicção que é um caminho viável para a comunhão divinahumana. Se não, seria rejeitada. Por outro lado, a política precisa preservar a possibilidade transcendental de rejeitar Deus. Se não, seria a igreja.

\footnotetext{
8 a Christian must accept certain restrictions within the public sphere that are not operative within a particular Christian community, and such restrictions are not imposed from outside, but are logically entailed in the Christian principle of divine-human communion.
} 


\section{0 "bem comum" como teologia política}

O livro, The Mystical as Political (A Mística como Política), pelo teólogo ortodoxo Aristotle Papanikolaou, é uma tentativa de refletir sobre os fundamentos teológicos da democracia liberal. Ele identificou três grandes áreas de debate (ou fricção) entre teologia ortodoxa e as propostas da democracia liberal. As vezes estas fricções são interpretadas pela própria democracia liberal como reações fundamentalistas, isto é contestação, rejeição ou desvios das noções modernas que fundamentam a democracia liberal, o discurso sobre direitos humanos e o conceito de bem comum em discursos filosóficos e teológicos ocidentais.

Papanikolaou não pretende seguir as distinções ontológicas utilizadas por muitas teologias políticas contemporâneas para distinguir propostas (e visões) teológicas da razão pública expressa em muitos debates sobre a democracia liberal. Isto é, ele não pretende trazer uma visão particular e particularmente cristã para agregar ao debate. Tampouco, ele não pretende defender a razão pública, que exclui o conteúdo teológico de discussões políticas. Em vez destas duas opções hegemônicas que dominam a teologia política contemporânea e a defesa da democracia liberal nas discussões da razão pública, Papanikolaou escolhe outro caminho.

O livro dele é abrangente. Neste artigo, focamos apenas no aspecto do "bem comum". O "bem comum" é fortemente associado ao iluminismo ocidental e a nova maneira de conceber a política em termos de igualdade, liberdade e fraternidade9. Ao mesmo tempo, na teologia ocidental o conceito de "bem comum" fundamenta a teologia social da igreja acrescentando os princípios cristãos de "caridade e solidariedade" a "igualdade, liberdade e fraternidade/sororiedade" das heranças iluministas. Papanikolaou demonstra que o "bem comum" é muito mais que isso. O "bem comum" teologicamente fundamentado na comunhão divina-humana (“deificação") oferece aos cristãos uma maneira de agir (em amor), uma maneira de ser (uma pessoa transcendental, única e autônoma) e uma maneira de participar (livre, digna e escatológica) na política.

9 O conceito recente de sororiedade agrega a estas 'dades'. 
A amor, conforme elaborado por Máximos, o Confessor, ajuda o cristão viver o "bem comum" em atos políticos. Amor, compreendido como reciprocidade relacional, necessita amor e não ódio para expressar a unidade humana diante de Deus e para manifestar comunhão divina-humana na política. O ser humano, enquanto compreendido como pessoa, na distinção de Zizioulas, ajuda o cristão a perceber e buscar o transcendental, na afirmação da sua unicidade e autonomia. Novamente, estes atos políticos só se tornam viáveis numa vivência do "bem comum". Por fim, o "bem comum" se manifesta na liberdade, dignidade e escatologia da política. Neste sentido, o "bem comum" faz manifesto “o cordeiro de Deus”, para emprestar as palavras de Bulgakov.

Aristotle Papnikolaou demonstra que a teologia política não precisar partir de pressupostos alheios à própria tradição teológica, seja ela ocidental ou oriental. Ele, também, demonstra que a teologia não precisa defender (ou rejeitar) o "bem comum" da tradição política ocidental acompanhando ou rejeitando a relação entre teologia e modernidade. E ele deixa claro que posições frequentemente interpretadas como "fundamentalistas" pela democracia ocidental poderiam ser equivocadas. No caso do "bem comum" examinado neste artigo, ele se torna mais rico com um fundamento teológico, abrindo novos horizontes de possibilidades tanto para as igrejas quanto para a razão pública nos debates contemporâneos sobre democracia liberal, direitos humanos e bem comum.

\section{Conclusão}

Aristotle Papanikolaou tem refletido sobre a relação entre teologia ortodoxa e política (democracia liberal) (PAPANIKOLAOU, 2014). Papanikolaou é a favor da democracia liberal e sua posição questiona a influência de orientalismos na construção de política e teologia da democracia liberal. Ele é a favor da democracia liberal por razões teológicas internas à teologia ortodoxa. Sua discussão da democracia liberal em termos teológicos engaja com o trabalho de Stanley Hauerwas e John Milbank. Mas Papanikolaou é crítico do antiliberalismo latente em Hauerwas e Milbank. 
Este artigo focou na discussão do bem comum na teologia do Papanikolaou. Porém, é importante notar que este aspecto do debate situa-se ao lado de discussões sobre a fundamentação de democracia liberal e o discurso sobre direitos humanos na democracia liberal no trabalho dele. Papanikolaou demonstra que o bem comum, longe de ser apenas fundamentado em filosofia, política e teologia ocidental e iluminista, também tem raízes e práticas na teologia oriental. Ele aprofunda as discussões da teologia ortodoxa sobre amor, pessoa e política, baseado na teologia de Máximos, o Confessor, John Zizioulas e Sergius Bulgakov, entre outros.

O trabalho teológico do Aristotle Papnikolaou demonstra que a teologia política não precisar partir de pressupostos alheios à própria tradição teológica, seja ela ocidental ou oriental. Ele, também, demonstra que a teologia não precisa defender (ou rejeitar) o "bem comum" da tradição política ocidental acompanhando ou rejeitando a relação entre teologia e modernidade. Em 'países ortodoxos' a teologia do Papanikolaou faz parte do grande debate dentro das igrejas e sociedades sobre a 'transição à democracia liberal'. Em países de tradição laica, a teologia dela oferece pistas importantes para contemplar os desafios da religiosidade fundamentalista crescente que coloca pressão na democracia liberal.

\section{REFERÊNCIAS}

AAGAARD, Anna Marie; BOUTEBEFF, Peter. Beyond the East-West Divide: the World Council of Churches and 'the Orthodox problem'. Genebra: WCC Publications, 2001.

ALFEYEV, Hilário. O mistério da fé: introdução à teologia dogmática ortodoxa. Petrópolis: Vozes, 2018.

ALI, Tariq. Confronto de fundamentalismos: cruzadas, jihads e modernidade. Rio de Janeiro: Editora Record, 2002.

APPBLEBY, R. Scott. Fundamentalists, Rigorists and Traditionalists. In: Papanikolaou, Aristotle e Demacopoulos, George E. (ed.). Fundamentalism or Tradition:

Christianity after Secularism. Nova York: Fordham University Press, 2020. p. 165-179.

BOFF, Leonardo. A Trindade, a sociedade e a libertação. Petrópolis: Vozes, 1986.

BULGAKOV, Sergius. The Lamb of God. Grand Rapids: Erdmanns, 2008. 
COAKLEY, Sarah. God, Sexuality and the Self: an essay 'On the Trinity’. Cambridge: Cambridge University Press. 2013.

DELIKOSTANTIS, Kostantinos. Orthodoxy Facing the Modern Secular State. In: STOECKL, Kristina; GABRIEL, Ingeborg; PAPANIKOLAOU, Aristotle. Political Theologies in Orthodox Christianity: common challenges - divergent positions. Londres: T \& T Clark, 2017. p. 243-251.

DEMACOPOULOS, George E.; PAPANIKOLAOU, Aristotle. Outrunning Constantine's Shadow. In: DEMACOPOULOS, George E.; PAPANIKOLAOU, Aristotle. Christianity, Democracy and the Shadow of Constantine. New York: Fordham University Press, 2017. p. 1-7.

GAVRILYUK, Paul L. Georges Florovsky and the Russian Religious

Renaissance. Oxford: Oxford University Press, 2015.

GVOSDEV, Nikolas K. Emperors and Elections: reconciling the Orthodox Tradition with Modern Politics. Nova York: Troitsa Books, 2000.

KALAITZIDIS, Pantelis. Orthodoxy and Political Theology. Genebra: WCC Publications, 2012.

MAKRIDES, Vasilios N. Orthodox Christian Rigorism: attempting to delineate a multifaceted phenomenon. Interdisciplinary Journal for Religion and Transformation in Contemporary Society, Schöningh, v. 2, n. 2, p. 216-252, 2016.

MARSDEN, George. M. Fundamentalism and American Culture. Nova York: Oxford University Press, 1980.

MARTY, Martin E. What is Fundamentalism: Theological Perspectives. In: KUNG, Hans; MOLTMANN, Jurgen. Concilium Special. Londres: SCM Press, 1992. p. 1-11.

MAXIMUS, the Confessor. Four Hundred Texts on Love. In: PALMER, G. E. H.; SHERRARD, Philip; WARE, Kalistos. The Philokalia: the complete text. Londres: Faber, 1984. v. 2, p. 52-113.

MILBANK, John. Theology and Social Theory: beyond secular reason. Londres: Blackwell, 2006.

MOLTMANN, Jürgen. A Igreja no poder do Espírito: uma contribuição à eclesiologia messiânica. Santo André: Academia Cristã, 2013.

PALMER, G.E.H; SHERRARD, Philip; WARE, Kalistos. The Philokalia: the complete text. Londres: Faber, 1984. v. 2.

PAPANIKOLAOU, Aristotle. The Mystical as Political. Notre Dame: University of Notre Dame Press, 2014.

ROUSSEAU, Jean-Jacques. Do contrato social. São Paulo: Folha de São Paulo, 2010. SAID, Edward. Orientalism. Londres: Penguin, 2003. 
SCHMEMANN, Alexander. The Historical Road of Eastern Orthodoxy. Nova York: Holt, Rinehart \& Winston, 1963.

SINNER, Rudolf von. The Churches and Democracy in Brazil: towards a public theology focused on citizenship. Eugene: Wipf and Stock, 2012.

SOLOVIEV, Vladimir. The Justification of the Good. Chattanooga: Catholic Resources, 2015.

THE JERUSALEM BIBLE. London: Darton, Longman \& Todd, 1966.

THE RUSSIAN ORTHODOX CHURCH'S Basic Teaching on Human Dignity, Freedom and Rights. Moscow: Moscow Patriarchate, 2008.

VOLF, Miroslav. A Public Faith: how followers of Christ should serve the common good. Grand Rapids: Brazos Press, 2011.

VOLF, Miroslav. After Our Likeness: The Church as the Image of the Trinity. Grand Rapids: Eerdmanns, 1997.

YANNARAS, Christos. Human Rights and the Orthodox Church. In: CLAPSIS, Emmanuel (org.). The Orthodox Churches in a Pluralistic World. Genebra: WCC Publications, 2004. p. 83-89.

ZIZOULAS, John. Being as Communion. Nova York: St Vladimir's Seminary Press, 1985 . 